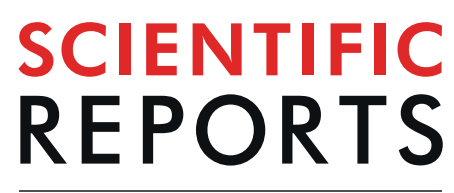

natureresearch

\title{
Polypyrrole-multi walled carbon nanotube hybrid material supported Pt NPs for hydrogen evolution from the hydrolysis of MeAB at mild conditions
}

\begin{abstract}
Yasar Karatas ${ }^{1}$, Esra Kuyuldar², Hilal Acidereli ${ }^{2}$, Mehmet Gulcan ${ }^{1 *}$ \& Fatih Sen $\mathbb{D}^{2 *}$
Herein, we report a facile method for the preparation of polypyrrole-multi walled carbon nanotube hybrid material including Pt nanoparticles (Pt@PPy-MWCNT NPs) and the use in methylamine borane (MeAB) for hydrolysis reaction at mild conditions. The prepared catalyst of Pt@PPy-MWCNT NPs was characterized by some advanced analytical methods. The catalytic experiments showed the Pt@PPy-MWCNT NPs can catalyze MeAB in aquatic solution with high catalytical performance at mild conditions. The reaction rate of catalytic hydrolysis with Pt@PPy-MWCNT NPs was found to be $-\mathrm{d}\left[\mathrm{CH}_{3} \mathrm{NH}_{2} \mathrm{BH}_{3}\right] / \mathrm{dt}=+\mathrm{d}\left[\mathrm{H}_{2}\right] / 3 \mathrm{dt}=\mathrm{k}_{\text {obs }}[\mathrm{Pt} @ P P y-\mathrm{MWCNT}]^{1.19}[\mathrm{MeAB}]^{0.88}$. The TOF value for the hydrolysis of MeAB catalyzed with Pt@PPy-MWCNT NPs was detected to be 10234.2 1/h (170.57 1/ $\mathrm{min}$ ) which is very high compared with TOF values found for other catalysts. Enthalpy, entropy and activation energy for the hydrolysis of $\mathrm{MeAB}$ were calculated to be $31.57 \mathrm{~kJ} \mathrm{~mol}^{-1},-119.97 \mathrm{~J} \mathrm{~mol}^{-1} \mathrm{~K}^{-1}$ and $34.27 \mathrm{~kJ} \mathrm{~mol}^{-1}$, respectively.
\end{abstract}

Hydrogen $\left(\mathrm{H}_{2}\right)$ is a fuel known all over the world as a fuel. The introduction of hydrogen in transportable electronic tools or carriers, it is required to use an $\mathrm{H}_{2}$ tank or "on board" in the production. Many studies have been reported about $\mathrm{H}_{2}$ storage methods ${ }^{1,2}$, obtaining $\mathrm{H}_{2}$ from hydrocarbons by the onboard method ${ }^{3,4}$. Furthermore, it is not possible to use all the methods due to the low volume and gravimetric efficiency of the storage of hydrogen, the high-temperature processability of hydrocarbons and the safety difficulties. In order to use $\mathrm{H}_{2}$ as fuel, it is necessary to make efficient storage of $\mathrm{H}_{2}$ with a reliable method. In recent studies, various different materials like sorbents ${ }^{5}$, metal hydrides ${ }^{6}$, and chemical hydrides process ${ }^{7-10}$ have been applied in the developing hydrogen storage. Among these materials, amine-boranes have taken great deal attention because their hydrogen contents are high and hydrogen release is applicable ${ }^{11}$. Recently, as an amine-borane compound, ammonia-borane $\left(\mathrm{NH}_{3}-\mathrm{BH}_{3}, \mathrm{AB}\right)$ has been noted as a high-potential source for hydrogen storage due to its hydrogen content of $19.6 \%$ wt., high durability, and environmentally friendly properties ${ }^{12,13}$. For this purpose, solid-phase thermolysis $^{14}$, catalytic hydrogen evolution in anhydrous solvents ${ }^{15}$, and hydrolysis ${ }^{16,17}$ can be used to provide the release of $\mathrm{H}_{2}$ from amine-borane compounds. The hydrolysis of the $\mathrm{AB}$ in the presence of the suitable catalyst may yield 3 moles of hydrogen per $1 \mathrm{~mol}$ of $\mathrm{AB}$ (Eq. (1)). This is one of the most appropriate methods of portable hydrogen storage ${ }^{18}$. Besides, methylamine borane $\left(\mathrm{CH}_{3} \mathrm{NH}_{2}-\mathrm{BH}_{3}, \mathrm{MeAB}\right)$, an amine borane derivative, has a hydrogen content of $11.1 \%$ by weight. Moreover, as given Eq. (2) $\mathrm{H}_{2}$ gas can take place with \% 100 yields. Although there are many studies related to the $\mathrm{AB}$ and its catalytic mechanism, the catalytic dehydrogenation mechanism of $\mathrm{MeAB}$ has remained unexplored ${ }^{19,20}$.

$$
\mathrm{NH}_{3} \mathrm{BH}_{3}+2 \mathrm{H}_{2} \mathrm{O} \underset{\mathrm{RT}}{\stackrel{\text { catalyst }}{\longrightarrow}} \mathrm{NH}_{4} \mathrm{BO}_{2}+3 \mathrm{H}_{2}
$$

\footnotetext{
${ }^{1}$ Chemistry Department, Faculty of Science, Van Yüzüncü Yıl University, Zeve Campus, 65080, Van, Turkey. ${ }^{2}$ Sen Research Group, Biochemistry Department, Faculty of Arts and Science, Dumlupınar University, Evliya Çelebi Campus, 43100, Kütahya, Turkey. *email: mehmetgulcan65@gmail.com; fatihsen1980@gmail.com
} 

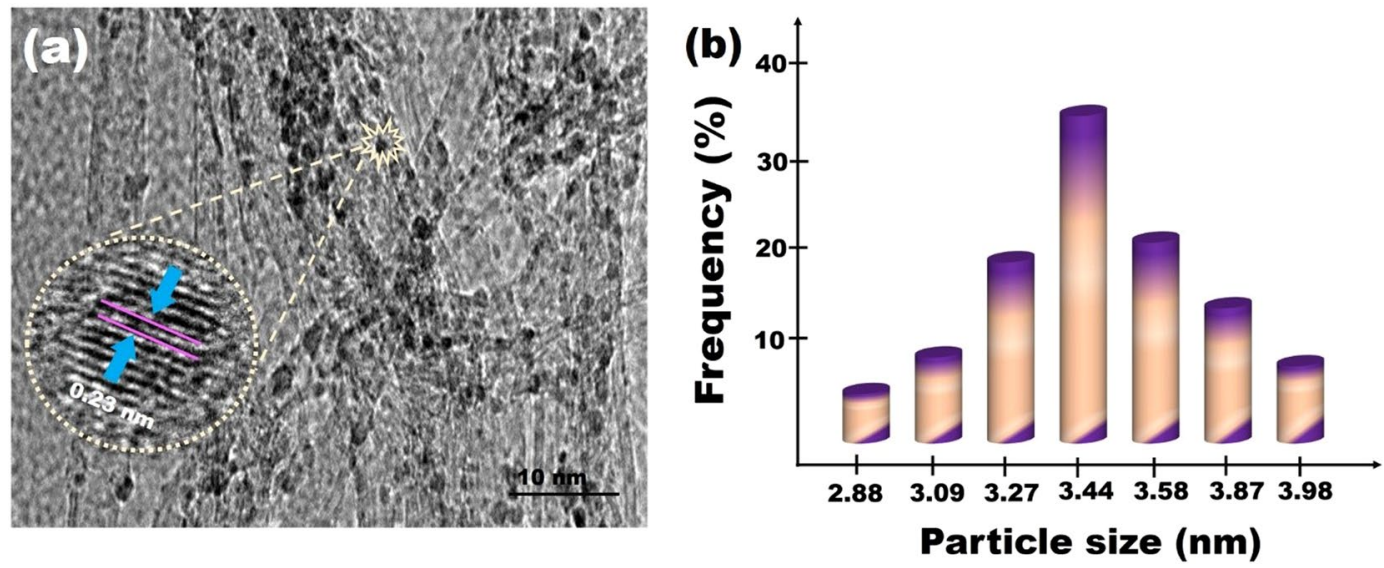

Figure 1. (a) TEM image and HR-TEM image and (b) particle size histogram of Pt@PPy-MWCNT NPs.

$$
\mathrm{CH}_{3} \mathrm{NH}_{2}-\mathrm{BH}_{3}+2 \mathrm{H}_{2} \mathrm{O} \underset{\mathrm{RT}}{\stackrel{\text { catalyst }}{\longrightarrow}} \mathrm{CH}_{3}\left(\mathrm{NH}_{3}\right) \mathrm{BO}_{2}+3 \mathrm{H}_{2}
$$

The Lewis acid, which is formed by taking the electron from the Lewis base, has much better controlled in the reduction rate, and selective reduction of the metal ions on conventional reducing chemicals such as in borohydrides ${ }^{21}$. The alkyl substitution at nitrogen is increased while the strength decreases as the following order: $\mathrm{Me}_{3} \mathrm{~N}-\mathrm{BH}_{3}<\mathrm{Me}_{2} \mathrm{NH}-\mathrm{BH}_{3}<\mathrm{MeNH}_{2}-\mathrm{BH}_{3}<\mathrm{BH}_{3}$. In literature, there are limited studies on developing reducing chemicals for the metal-based nanoparticles synthesis ${ }^{22}$. Thus, the studies are carried out to develop low-cost, high-efficiency and stable catalysts for hydrogen production. Although there are many studies related to the development of novel catalysts, only a few studies are given associated with hybrid materials and their usage as catalyst systems ${ }^{14-22}$. For this reason, in this study, a polypyrrole-multi walled carbon nanotube hybrid material supported Pt nanoparticle (Pt@PPy-MWCNT NPs) was used for hydrogen evaluation from the hydrolysis of $\mathrm{MeAB}$ and complete conversion of $\mathrm{MeAB}$ to products as seen in equation 2 was achieved. Using trace of concentration of Pt@PPy-MWCNT catalyst in an aquatic mixture of MeAB at room temperature, $3 \mathrm{mmol}_{2}$ release from 1 mmol MeAB was achieved. Additionally, the kinetic studies of MeAB catalyzed Pt@PPy-MWCNT NPs were also performed and activation parameters including entropy $\left(\Delta \mathrm{S}^{\#}\right)$, enthalpy $\left(\Delta \mathrm{H}^{\#}\right)$, activation energy $(\mathrm{Ea})$ were calculated.

\section{Results and Discussion}

Structural and morphological features of Pt@PPy-MWCNT NPs. Some sophisticated techniques, including TEM, XRD, Raman spectroscopy etc have been used to study the surface and structural composition of PPy-MWCNT and Pt@PPy-MWCNT NPs. Detail characterization and explanations of PPy-MWCNT have attached to the supporting information and shown in Figs. S1-S3. TEM and HR-TEM images of the Pt@PPyMWCNT NPs are given in Fig. 1a and S4. The particle size histogram for Pt@PPy-MWCNT NPs was shown in Fig. 1b. TEM analysis detected a goog Platinium dispersion on the support and a spherical Pt metals shape having a mean particle-sized ranging from 3.44 to $4.07 \mathrm{~nm}$ that show few agglomerations have occurred on the surface of PPy-MWCNT supports (Fig. 1a,b). The enlarged image indicates that the surface consists of a coating of platinum nanoparticles with inter-fringe distances of $0.23 \mathrm{~nm}$, equal to the fcc platinum $\mathrm{Pt}(111)$ plane $^{21}$.

XRD studies were carried out to detect the crystalline formation of Pt@PPy-MWCNT NPs (containing $2.78 \pm 0.02 \mathrm{wt} \% \mathrm{Pt}$ ). XRD analysis, given in Fig. 2, indicated no composition change in PPy-MWCNT because of decorated with reduced platinum metals. It can be said that Pt@PPy-MWCNT NPs maintained their platin metals and PPy-MWCNT support material based composition after preparation study. Briefly, XRD studies revealed that there was no change of chemical composition in the form of PPy-MWCNT that make Pt@PPy-MWCNT an ideal nanoparticle. On the other hand, diffraction peaks of Pt@PPy-MWCNT NPs in the XRD pattern (Fig. 2(c)) at $2 \theta=39.9^{\circ}, 46.3^{\circ}, 67.5^{\circ}, 81.6^{\circ}$ and $85.5^{\circ}$, compatible with (111), (200), (220), (311) and (222), respectively. These data detect the face-centered cubic form of Pt that ascribed to (JCPDS Card 04-0802) shows Pt crystalline form of $\mathrm{Pt}^{22,23}$.

The representation of the MWCNT and PPy-MWCNT supported platinum nanoparticles by Raman Spectroscopy is shown in Fig. 3. As it can see in Fig. 3, the peaks of carbon products corresponding to the D and $\mathrm{G}$ band are observed at $1349 \mathrm{~cm}^{-1}$ and $1589 \mathrm{~cm}^{-1}$, respectively. The density ratios of $\mathrm{D}-\mathrm{G}$ bands $\left(\mathrm{I}_{\mathrm{D}} / \mathrm{I}_{\mathrm{G}}\right)$ are investigated to identify the rate of graphitization and the error margin of the carbon-containing materials. $\mathrm{I}_{\mathrm{D}} / \mathrm{I}_{\mathrm{G}}$ ratio is increased from 1.24 to 1.31 which means that the MWCNT was functionalized by PPy and Pt nanoparticles. The functionalization of MWCNT results in increasing of D band peak density.

The oxidation and electronic state of platin metals present in the composition of the prepared catalyst (Pt@ PPy-MWCNT) were examined using X-ray photoelectron spectroscopy (XPS). The XPS results given in Fig. 4 show that the two peaks at the 71.0 and $72.9 \mathrm{eV}$ for the $4 \mathrm{f}$ region are attributed to the metallic $\mathrm{Pt}(0)$ and $\mathrm{Pt}$ (II) platinum types ${ }^{22}$. 


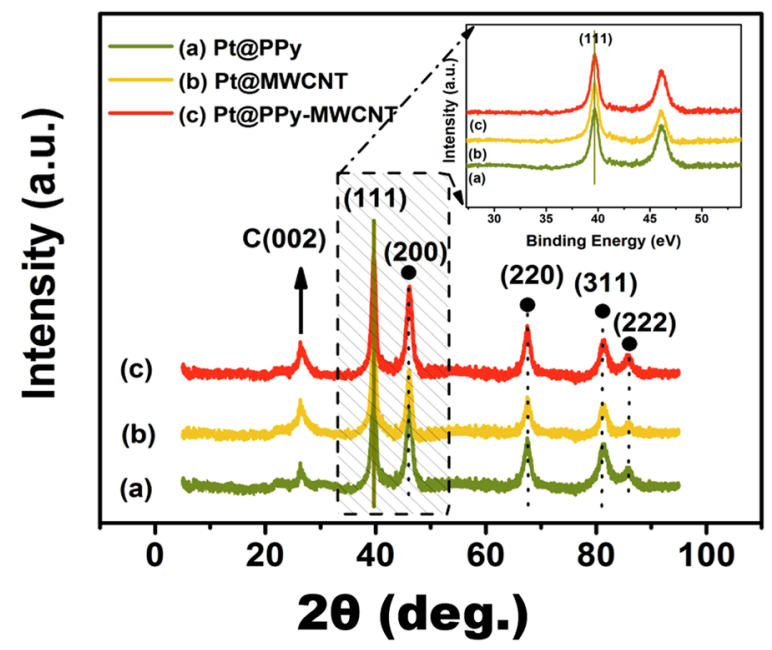

Figure 2. XRD analyses of (a) Pt@Ppy, (b) Pt@MWCNT and (c) Pt@PPy-MWCNT NPs.

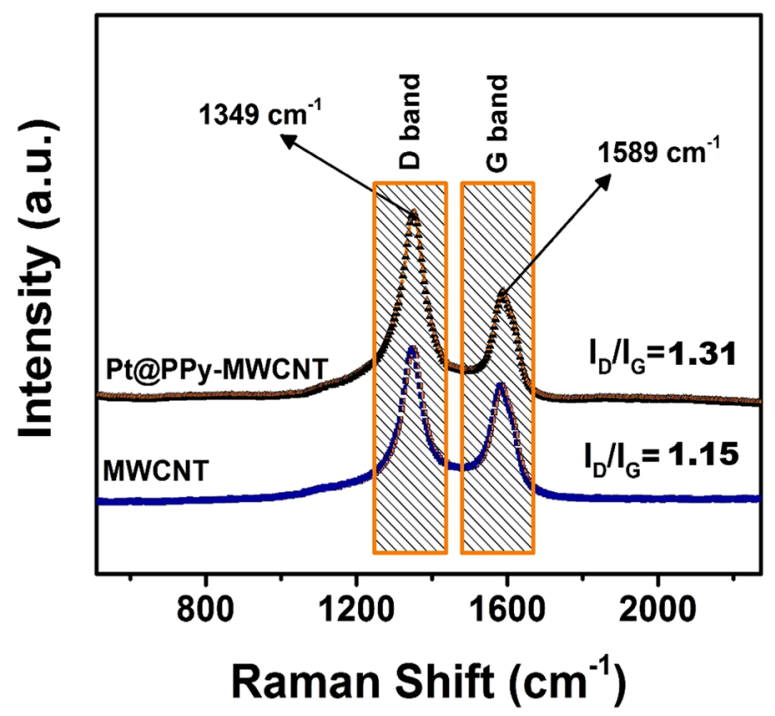

Figure 3. Raman spectra of MWCNT and Pt@PPy-MWCNT NPs.

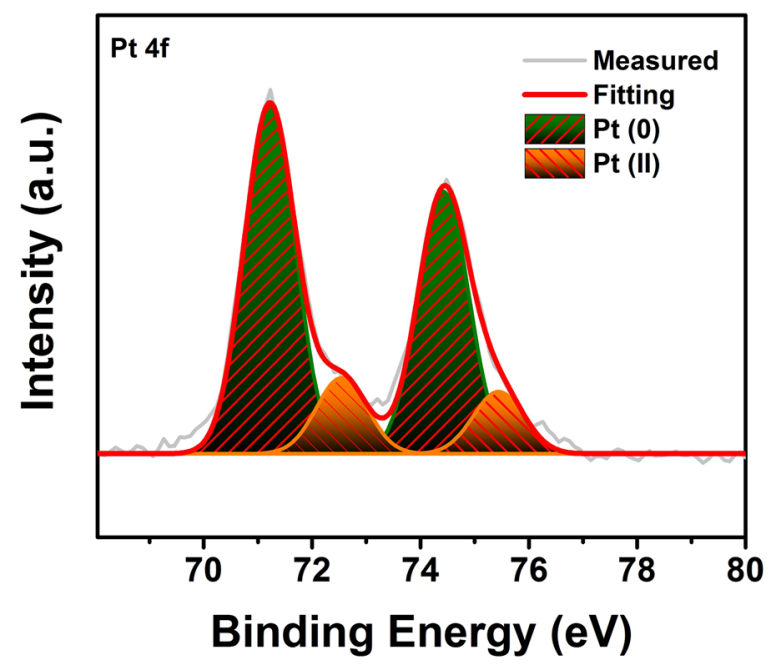

Figure 4. Pt $4 \mathrm{f}$ region of X-ray photoelectron spectrum of Pt@PPy-MWCNT NPs. 


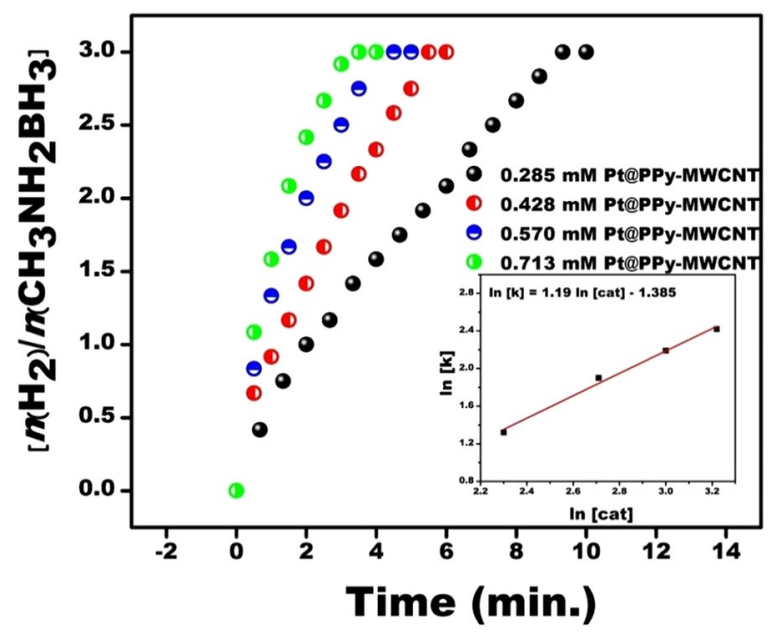

Figure 5. Plot of ration of $\mathrm{nH}_{2} / \mathrm{CH}_{3} \mathrm{NH}_{2} \mathrm{BH}_{3}$ versus time for $\mathrm{MeAB}\left(50 \mathrm{mM}\right.$ in $\left.5 \mathrm{~mL} \mathrm{H}_{2} \mathrm{O}\right)$ and plot of lnk versus $\ln$ [cat.] (inset) with different Pt@Py-MWCNT NPs ([Pt@PPy-MWCNT NPs] = 0.285, 0.428, 0.570 and $0.713 \mathrm{mM}$ ) for $\mathrm{MeAB}$ hydrolysis at mild conditions.

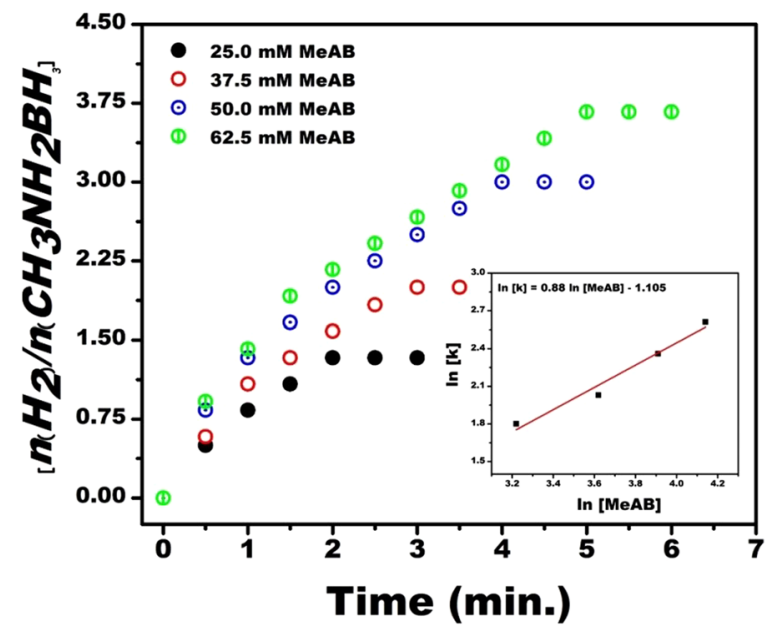

Figure 6. Plot of $\mathrm{nH}_{2} / \mathrm{CH}_{3} \mathrm{NH}_{2} \mathrm{BH}_{3}$ versus time for MeAB $(50 \mathrm{mM})$ containing Pt@PPy-MWCNT NPs ([Pt@ PPy-MWCNT NPs $]=5.7 \times 10^{-4} \mathrm{M}$ in $5 \mathrm{~mL} \mathrm{H}_{2} \mathrm{O}$ ), and plot of lnk versus $\ln [\mathrm{MeAB}]$ (inset) for the hydrolysis of $\mathrm{MeAB}$ including various $\mathrm{MeAB}$ amounts $([\mathrm{MeAB}]=25,37.5,50$ and $62.5 \mathrm{mM})$ at mild conditions.

The hydrolysis of MeAB catalyzed by Pt@PPy-MWCNT NPs. The catalytical reaction experiments were conducted using a set composed of a flask tube having two necks (Schlenk) connected to a graduated tube for MeAB dehydrogenation catalyzed Pt@PPy-MWCNT NPs. One neck connected to a circulator operating to adjunct temperature and the other connected to the graduated tube to determine the released hydrogen volume. A standard reaction procedure initiated by moving the necessary quantity of catalyst to Schlenk stirred for $15 \mathrm{~min}$ at $600 \mathrm{rpm}$ to achieve a temperature of equilibrium. At the end of this time, $11.25 \mathrm{mg}$ of MeAB was applied to the reaction medium, and Schlenk was quickly shut down and the reaction started with a chronometer. The released $\mathrm{H}_{2}$ amount was recorded by observing a change of water level in the graduated tube. To detect the effect of catalyst amount to the $\mathrm{MeAB}$ catalytical reaction, different catalyst concentrations from $2.85 \times 10^{-4} \mathrm{M}$ to $7.13 \times 10^{-4} \mathrm{M}$ were tested at room conditions and the finding of these experimental results is given in Fig. 5 . The MeAB reaction catalyzed with Pt@PPy-MWCNT NPs initiated very fast and not seen any induction given in Fig. 5 and $\mathrm{H}_{2}$ release rated was increased with increasing catalyst concentration. Also, as seen almost the whole hydrogen in the composition of MeAB with the presence of Pt@PPy-MWCNT NPs was released in 2-10 min. The findings of catalyst concentration were evaluated and a linear plot of $\ln [\mathrm{k}]$ versus $\ln$ [cat.] plot was obtained as the seen inlet of Fig. 5 having 1.19 slope. The hydrolysis reaction of MeAB catalyzed by Pt@PPy-MWCNT NPs was the almost first order $\left(1.19^{\text {th }}\right.$-order) based on the concentration of Pt@PPy-MWCNT NPs.

To detect the effect of substrate concentration on the $\mathrm{MeAB}$ catalytical reaction, different MeAB concentrations in the range of $25-62,5 \mathrm{mM}$ were tested at room conditions and the finding of these experimental results is seen in Fig. 6. If the graph is plotted for lnk versus ln [MeAB], a linear line will be obtained as shown in Fig. 6 (Inset) and its slope was 0.88 . This means the MeAB reaction rate catalyzed by Pt@PPy-MWCNT NPs was the 
(a)

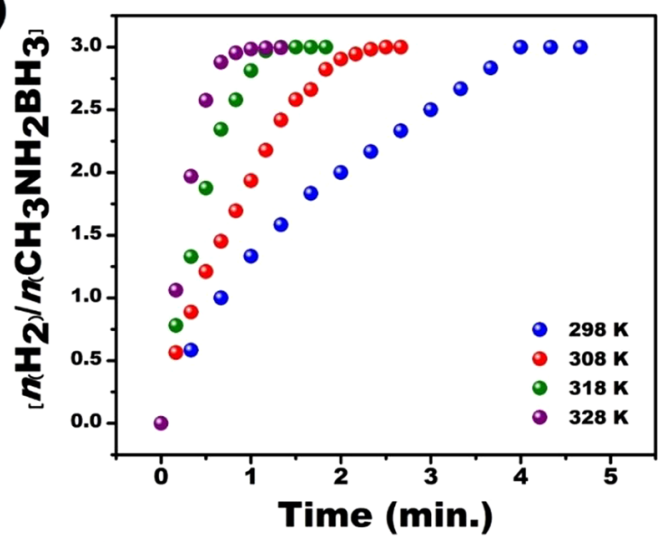

(b)

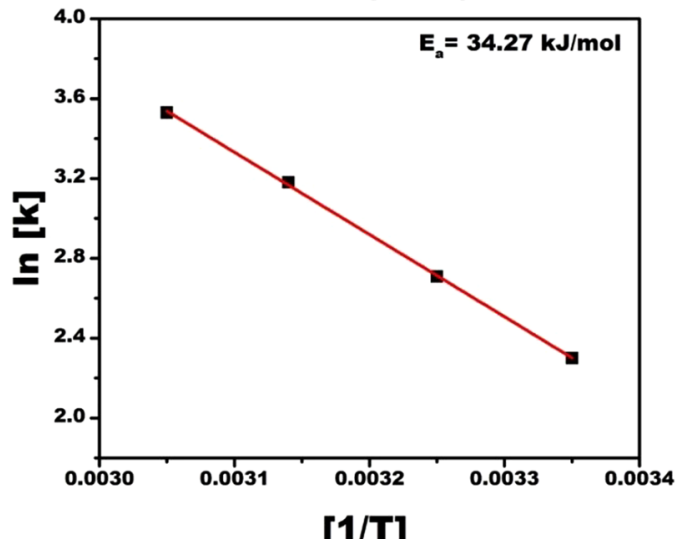

(c)

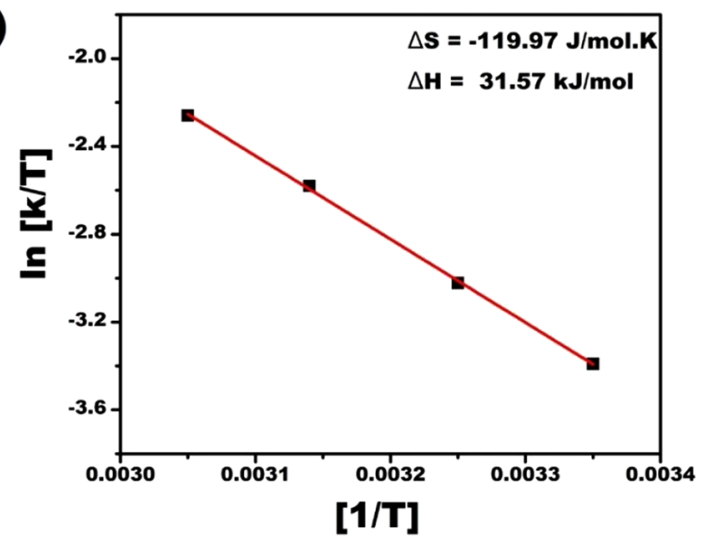

Figure 7. (a) Plot of $\mathrm{nH}_{2} / \mathrm{CH}_{3} \mathrm{NH}_{2} \mathrm{BH}_{3}$ versus time for $\mathrm{MeAB}\left(50 \mathrm{mM}\right.$ in $\left.5 \mathrm{~mL} \mathrm{H}_{2} \mathrm{O}\right)$ beginning with Pt@PPy-

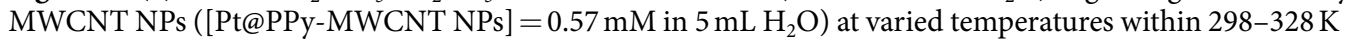
range, (b) Arrhenius, and (c) Eyring plots of the reactions.

$0.88^{\text {th }}$-order based on the concentration of MeAB. In the light of these results, the equation of the catalytic hydrolysis rate of MeAB including Pt@PPy-MWCNT NPs was attained as follows;

$$
-\mathrm{d}\left[\mathrm{CH}_{3} \mathrm{NH}_{2}-\mathrm{BH}_{3}\right] / \mathrm{dt}=+\mathrm{d}\left[\mathrm{H}_{2}\right] / 3 \mathrm{dt}=\mathrm{k}_{\text {obs }}[\mathrm{Pt} @ \mathrm{PPy}-\mathrm{MWCNT}]^{1.19}[\mathrm{MeAB}]^{0.88}
$$

To detect the effect of temperature to the $\mathrm{MeAB}$ catalytical reaction, different catalyst amounts in the range of $25-55^{\circ} \mathrm{C}$ were tested at room conditions and the finding of these experimental results is seen in Fig. 7. In these experiments, $50 \mathrm{mM} \mathrm{CH}_{3} \mathrm{NH}_{2}-\mathrm{BH}_{3}$ and $0.57 \mathrm{mM}$ Pt@PPy-MWCNT NPs were used as common parameters. In Fig. 7, the hydrogen release rate was improved by increased temperature. The results obtained from experiments performed at different temperatures were employed to detect activation parameters like $\Delta \mathrm{S}^{\#}$, Ea and $\Delta \mathrm{H}^{\#} \mathrm{using}$ Arrhenius and Eyring plots of Fig. 7. These data were found to be $\Delta \mathrm{S}^{\#}=-119.97 \mathrm{~J} \mathrm{~mol}^{-1} \mathrm{~K}^{-1}, \mathrm{Ea}=34.27 \mathrm{~kJ} \mathrm{~mol}^{-1}$ and $\Delta \mathrm{H}^{\#}=31.57 \mathrm{~kJ} \mathrm{~mol}^{-1}$.

In order to evaluate the catalytical reusable and durable of Pt@PPy-MWCNT, the reuse experiments of catalysts were done and examined as shown in Fig. S5. A typical reuse run was conducted by taking the same amount of catalyst and substrate as tested the other common experiments. The reaction was initiated with this amount 


\begin{tabular}{|l|l|l|l|}
\hline Catalyst & TOF* & Ea** & Ref. \\
\hline $\mathrm{Cu}_{12.6} @ \mathrm{Fe}_{9.8} \mathrm{Co}_{38.8} \mathrm{Ni}_{38.8} /$ graphene $^{*}$ & $\mathrm{ND}$ & 39.69 & 25 \\
\hline $\mathrm{Cu}_{0.2} @ \mathrm{Co}_{0.8} / \mathrm{rGO}$ & $\mathrm{ND}$ & 55.9 & 26 \\
\hline $\mathrm{Rh} / \mathrm{graphene}$ & 146 & 16.4 & 27 \\
\hline $\mathrm{Co}_{0.9} \mathrm{Ni}_{0.1} /$ graphene NPs & $\mathrm{ND}$ & 26.78 & 28 \\
\hline $\mathrm{Ru}_{1} @ \mathrm{Ni}_{7.5} /$ graphene NPs & 231 & 37.01 & 29 \\
\hline $\mathrm{Ru} / \mathrm{MCM}^{-41}$ & 47.60 & $\mathrm{ND}$ & 30 \\
\hline $\mathrm{Cu}_{0.1} @ \mathrm{Co}_{0.45} \mathrm{Ni}_{0.45} /$ graphene NPs & $\mathrm{ND}$ & 50.75 & 31 \\
\hline $\mathrm{Ag} @ \mathrm{CoNiFe} /$ graphene & $\mathrm{ND}$ & 33.53 & 32 \\
\hline $\mathrm{Rh} \mathrm{Ni}_{7.5} /$ graphene & $\mathrm{ND}$ & 31.26 & 33 \\
\hline $\mathrm{Ru} @ \mathrm{Co} / \mathrm{graphene} \mathrm{NPs}$ & 226 & $\mathrm{ND}$ & 34 \\
\hline $\mathrm{Cu} /$ nano-MIL-101 & 4.28 & 34.1 & 35 \\
\hline $\mathrm{Rh} @ \mathrm{PVP} 40$ & 185.91 & 43.88 & 24 \\
\hline $\mathrm{Ru}-\mathrm{Rh} @ \mathrm{PVP}$ & 206.20 & 43.5 & 36 \\
\hline $\mathrm{Pt} @ \mathrm{PPy}-\mathrm{MWCNT} \mathrm{NPs}$ & $\mathbf{1 7 0 . 5 7}$ & $\mathbf{3 4 . 2 7}$ & This study \\
\hline
\end{tabular}

Table 1. Comparisons of catalytic activities of the catalysts used for the hydrolysis of MeAB. *Turn-over frequency $\left(\mathrm{mol} \mathrm{H}_{2}\right.$ mol catalyst $\left.{ }^{-1} \mathrm{~min}^{-1}\right)$, **Activation energy $\left(\mathrm{kJ} \mathrm{mol}^{-1}\right)$, $\mathrm{ND}$ (Not Demonstrated).

of Pt@PPy-MWCNT catalyst and MeAB substrate and waited until the catalytical reaction finished. After the reaction was ended, the same amount of support material taken at the initial was added to the first reaction medium and the reaction was initiated again at room conditions. This procedure was repeated 5 times, the run results are given in Fig. S5, the initial catalytical performance of Pt@PPy-MWCNT catalyst was detected to be $85.4 \%$ after the $5^{\text {th }}$ run. The XRD and TEM characterization of Pt@PPy-MWCNT after reuse were shown in Figs. S6 and S7. The results indicate that there is a small amount of agglomeration after reuse as shown in these figures. The initial TOF value for the hydrolysis of MeAB catalyzed with Pt@PPy-MWCNT NPs as a catalyst was detected to be $10234.2 \mathrm{~h}^{-1}\left(170.57 \mathrm{~min}^{-1}\right)$ that is very high compared with TOF values found for other catalysts as given in Table 1 . With this study, we showed the complete conversation MeAB to the products can be achieved using Pt@PPy-MWCNT NPs as a catalyst under mild conditions. We can interpret these results as the synergic effects between supports and metals, high metal contents and ultrafine chemical compositions maybe some of the main reasons for a good catalytical activity. The good stabilization of PPy-MWCNT with platinum metals and enhanced active surface side on the catalysts (according to characterization studies) can be the other reasons in high catalytical performance of Pt@PPy-MWCNT catalyst.

\section{Experimental}

Preparation of methylamine-borane $\left(\mathrm{CH}_{3} \mathrm{NH}_{2} \mathrm{BH}_{3}, \mathrm{MeAB}\right)$. MeAB was used for kinetic studies as substrate $^{24}$. For this aim, 0.1 moles of $(3.88 \mathrm{~g})$ sodium borohydride $\left(\mathrm{NaBH}_{4}\right)$ and $200 \mathrm{~mL}$ anhydrous tetrahydrofuran (THF) were placed in a $250 \mathrm{~mL}$ of volume two-neck flask. The resulting mixture was stirred for $30 \mathrm{~min}$ at $298 \mathrm{~K}, 0.1 \mathrm{~mol}(6.752 \mathrm{~g})$ of methylamine hydrochloride $\left(\mathrm{CH}_{3} \mathrm{NH}_{2} \cdot \mathrm{HCl}\right)$ was transferred in it (Eq. (3)). The reaction maintained for 24 hours in the $\mathrm{N}_{2}$ atmosphere at $298 \mathrm{~K}$. 24 hours later, and the solid product was separated. The residual liquid phase was evaporated to obtain THF. A $100 \mathrm{~mL}$ dry sample of ether was transferred to the latest solution and stirred at $0^{\circ} \mathrm{C}$ for $2 \mathrm{~h}$, and the solid was filtered. The obtained liquid ether was left to evaporate about $20^{\circ} \mathrm{C}$. After the complete evaporation of, the white solid crystalline formation was observed.

$$
\mathrm{CH}_{3} \mathrm{NH}_{2} . \mathrm{HCl}+\mathrm{NaBH}_{4} \underset{N_{2}, 24 \mathrm{~h}}{\stackrel{\text { anhydrous THF }}{\longrightarrow}} \mathrm{CH}_{3} \mathrm{NH}_{2}-\mathrm{BH}_{3}+\mathrm{H}_{2}+\mathrm{NaCl}
$$

Synthesis of polypyrrole-multi walled carbon nanotube (PPy-MWCNT) hybrid support material. The following procedure was followed for the preparation of PPy-MWCNT hybrid support material: $20 \mathrm{mg}$ of polypyrrole was added into $25 \mathrm{~mL}$ of water and dissolved in ultrasonication for 1 hour. In another beaker, $20 \mathrm{mg}$ of MWCNT was added into $24 \mathrm{~mL}$ of water and dissolved by ultrasonication for 1 hour. The obtained solutions were brought together and kept for 30 minutes until thoroughly mixed. The resulting homogeneous mixture was taken into the Schlenk tube, and the synthesis mechanism was established. The ambient conditions were kept stable with the help of water circulation and $\mathrm{N}_{2}$ gas. $\mathrm{N}_{2}$ gas was allowed to stir for 1 hour in a trapped Schlenk tube. After this process, the final step of the synthesis was carried out by adding reductant. The solution was allowed to stir under reflux for 12 hours at $100^{\circ} \mathrm{C}$. After 12 hours, the prepared solution was washed with ethanol or water to perform the washing operation by centrifugation. After repeated washing, it was allowed to dry in a petri dish and dried under vacuum.

Synthesis of polypyrrole-multi walled carbon nanotube hybrid material supported Pt metal nanoparticles (Pt@PPy-MWCNT NPs). PPy-MWCNT nanocomposites synthesis was performed using in situ chemical pyrrole monomer polymerization in an aqueous solution containing dispersed MWCNTs. For this purpose, firstly, $24 \mathrm{ml}$ deionized water and $20 \mathrm{mg}$ MWCNTs previously treated with acids were sonicated for 1 hour. The respective suspension was then added to $25 \mathrm{ml}$ of pyrrole and sonicated for 1 hour. The mass ratio of 
the pyrrole monomer/MWCNTs was 1 . An oxidant, ammonium persulfate (APS) aqueous solution was gradually applied to the mixture. The reaction took almost 30 minutes under magnetic stirring. Finally, methanol was added to be able to finish the pyrrole polymerization reaction. After that, a simple, one-step method was applied for the preparation of platinum nanoparticles supported on PPy-MWCNT. Simply, a solution was prepared by dissolving $0.0252 \mathrm{mmol}$ of $\mathrm{K}_{2} \mathrm{PtCl}_{6}$ and $0.025 \mathrm{mg} / \mathrm{mL}$ of PPy-MWCNT support in $5 \mathrm{ml}$ of water. The prepared solution was mixed for $2 \mathrm{~h}$ and then a $15 \mathrm{~mL}$ of sodium boron hydride was added as a reducing agent $\left(\mathrm{NaBH}_{4}\right)$ was transferred into the latest solution. After reducing $\mathrm{Pt}$ (IV) into Pt (0), the resulting solution was filtered, and the solid sample was cleaned by washing using abundant pure water. The catalyst sample was dried in a vacuumed oven at $80^{\circ} \mathrm{C}$. The dried samples were stored for further using of experiments conducted with different temperatures, substrate concentrations and catalyst concentrations.

\section{Conclusions}

In this paper, we showed that Pt@PPy-MWCNT NPs can be prepared by using a simple and facile approach and effectively used in the MeAB hydrolysis reaction at mild conditions. The catalytic experiments showed the Pt@PPy-MWCNT NPs can catalyst MeAB in aquatic solution and with high catalytical performance at mild conditions. The reaction rate of catalytic hydrolysis of MeAB include Pt@PPy-MWCNT NPs was found to be $-\mathrm{d}\left[\mathrm{CH}_{3} \mathrm{NH}_{2} \mathrm{BH}_{3}\right] / \mathrm{dt}=+\mathrm{d}\left[\mathrm{H}_{2}\right] / 3 \mathrm{dt}=\mathrm{k}_{\text {obs }}[\mathrm{Pt} @ \mathrm{PPy}-\mathrm{MWCNT}]^{1.19}[\mathrm{MeAB}]^{0.88}$. The TOF value for the hydrolysis of MeAB catalyzed as a catalyst using Pt@PPy-MWCNT NPs was detected to be $10234.2 \mathrm{~h}^{-1}\left(170.57 \mathrm{~min}^{-1}\right)$ that is very high compared with TOF values found for other catalysts as given in Table 1 . The main reason for this high catalytic performance can be the synergistic effect formed between Pt metals and PPy-MWCNT support materials. Due to this superior catalytic performance of Pt@PPy-MWCNT NPs in the hydrolysis of MeAB, the prepared this catalyst can be a good candidate for hydrogen evolution from hydrogen storage materials in the usage of fuel cells. Some parameters of activation such as enthalpy, entropy and activation energy for this important reaction were calculated to be $31.57 \mathrm{~kJ} \mathrm{~mol}^{-1},-119.97 \mathrm{~J} \mathrm{~mol}^{-1} \mathrm{~K}$ and $34.27 \mathrm{~kJ} \mathrm{~mol}^{-1}$, respectively.

Received: 20 May 2019; Accepted: 23 November 2019;

Published online: 06 December 2019

\section{References}

1. Chen, P., Xiong, Z., Luo, J., Lin, J. \& Lee Tan, K. Interaction of hydrogen with metal nitrides and imides. Nature, https://doi. org/10.1038/nature01210 (2002).

2. Rosi, N. L. et al. Hydrogen storage in microporous metal-organic frameworks. Science (80-.), https://doi.org/10.1126/ science.1083440 (2003).

3. Deluga, G. A., Salge, J. R., Schmidt, L. D. \& Verykios, X. E. Renewable Hydrogen from Ethanol by Autothermal Reforming. Science (80-.), https://doi.org/10.1126/science.1093045 (2004).

4. Schlesinger, H. I. et al. Sodium Borohydride, Its Hydrolysis and its Use as a Reducing Agent and in the Generation of Hydrogen. J. Am. Chem. Soc. https://doi.org/10.1021/ja01097a057 (1953).

5. Wang, L. \& Yang, R. T. Molecular hydrogen and spiltover hydrogen storage on high surface area carbon sorbents. Carbon N. Y, https://doi.org/10.1016/j.carbon.2011.09.049 (2012).

6. Sheppard, D. A. et al. Hydriding characteristics of $\mathrm{NaMgH} 2 \mathrm{~F}$ with preliminary technical and cost evaluation of magnesium-based metal hydride materials for concentrating solar power thermal storage. RSC Adv, https://doi.org/10.1039/c4ra01682c (2014).

7. Gim, B. \& Kim, J. W. Multi-criteria evaluation of hydrogen storage systems for automobiles in Korea using the fuzzy analytic hierarchy process. Int. J. Hydrogen Energy, https://doi.org/10.1016/j.ijhydene.2014.03.066 (2014).

8. Şen, B., Demirkan, B., Levent, M., Şavk, A. \& Şen, F. Silica-based Monodisperse PdCo Nanohybrids as Highly Efficient and Stable Nanocatalyst for Hydrogen Evolution Reaction. Int. J. Hydrogen Energy 43, 20234-20242 (2018).

9. Sen, B., Şavk, A. \& Sen, F. Highly efficient monodisperse Pt nanoparticles confined in the carbon black hybrid material for hydrogen liberation. J. Colloid Interface Sci. 520, 112-118 (2018).

10. Şen, B. et al. Metal-organic frameworks based on monodisperse palladium cobalt nanohybrids as highly active and reusable nanocatalysts for hydrogen generation. Int. J. Hydrogen Energy 44, 2988-2996 (2019).

11. Luo, W., Zakharov, L. N. \& Liu, S. Y. 1,2-BN cyclohexane: Synthesis, structure, dynamics, and reactivity. J. Am. Chem. Soc, https:// doi.org/10.1021/ja206497x (2011).

12. Jiang, H.-L. \& Xu, Q. Catalytic hydrolysis of ammonia borane for chemical hydrogen storage. Catal. Today 170, 56-63 (2011).

13. Karataş, Y., Gülcan, M., Çelebi, M. \& Zahmakiran, M. Pd(0) Nanoparticles Decorated on Graphene Nanosheets (GNS): Synthesis, Definition and Testing of the Catalytic Performance in the Methanolysis of Ammonia Borane at Room Conditions. ChemistrySelect, https://doi.org/10.1002/slct.201701616 (2017).

14. Choi, Y. J. et al. Kinetics study of solid ammonia borane hydrogen release-modeling and experimental validation for chemical hydrogen storage. Phys. Chem. Chem. Phys, https://doi.org/10.1039/c3cp55280b (2014).

15. Fortman, G. C., Slawin, A. M. Z. \& Nolan, S. P. Highly active iridium(III)-NHC system for the catalytic B-N bond activation and subsequent solvolysis of ammonia-borane. Organometallics, https://doi.org/10.1021/om2007437 (2011).

16. Wang, J., Qin, Y. L., Liu, X. \& Zhang, X. B. In situ synthesis of magnetically recyclable graphene-supported Pd@Co core-shell nanoparticles as efficient catalysts for hydrolytic dehydrogenation of ammonia borane. J. Mater. Chem, https://doi.org/10.1039/ c2jm32229c (2012).

17. Konuş, N., Karataş, Y. \& Gulcan, M. In Situ Formed Ruthenium(0) Nanoparticles Supported on TiO ${ }_{2}$ Catalyzed Hydrogen Generation from Aqueous Ammonia-Borane Solution at Room Temperature under Air. Synth. React. Inorganic, Met. Nano-Metal Chem, https://doi.org/10.1080/15533174.2014.988808 (2016).

18. Cao, N., Luo, W. \& Cheng, G. One-step synthesis of graphene supported Ru nanoparticles as efficient catalysts for hydrolytic dehydrogenation of ammonia borane. Int. J. Hydrogen Energy, https://doi.org/10.1016/j.ijhydene.2013.06.125 (2013).

19. Yang, L., Luo, W. \& Cheng, G. Graphene-supported Ag-based core-shell nanoparticles for hydrogen generation in hydrolysis of ammonia borane and methylamine borane. ACS Appl. Mater. Interfaces, https://doi.org/10.1021/am402373p (2013).

20. Kanat, M., Karataş, Y., Gülcan, M. \& Anıl, B. Preparation and detailed characterization of zirconia nanopowder supported rhodium (0) nanoparticles for hydrogen production from the methanolysis of methylamine-borane in room conditions. Int. J. Hydrogen Energy 43, 22548-22556 (2018).

21. Babu Kalidindi, S., Sanyal, U. \& Jagirdar, B. R. Chemical Synthesis of Metal Nanoparticles Using Amine-Boranes. ChemSusChem 4, 317-324 (2011).

22. Sanyal, U., Davis, D. T. \& Jagirdar, B. R. Bimetallic core-shell nanocomposites using weak reducing agent and their transformation to alloy nanostructures. Dalt. Trans, https://doi.org/10.1039/c3dt33086a (2013). 
23. Yang, Z., Cheng, F., Tao, Z., Liang, J. \& Chen, J. Decreasing the thermal dehydrogenation temperature of methylamine borane (MeAB) by mixing with poly(methyl acrylate) (PMA). Int. J. Hydrogen Energy, https://doi.org/10.1016/j.ijhydene.2012.01.134 (2012).

24. Gulcan, M. \& Karataş, Y. Synthesized polyvidone-stabilized $\mathrm{Rh}(0)$ nanoparticles catalyzed the hydrolytic dehydrogenation of methylamine-borane in ambient conditions. New J. Chem, https://doi.org/10.1039/c7nj02481a (2017).

25. Meng, X. et al. Decoration of graphene with tetrametallic Cu@FeCoNi core-shell nanoparticles for catalytic hydrolysis of amine boranes. RSC Adv, https://doi.org/10.1039/c4ra04894f (2014).

26. Du, Y., Cao, N., Yang, L., Luo, W. \& Cheng, G. One-step synthesis of magnetically recyclable rGO supported Cu@Co core-shell nanoparticles: Highly efficient catalysts for hydrolytic dehydrogenation of ammonia borane and methylamine borane. New J. Chem, https://doi.org/10.1039/c3nj00552f (2013).

27. Shen, J., Yang, L., Hu, K., Luo, W. \& Cheng, G. Rh nanoparticles supported on graphene as efficient catalyst for hydrolytic dehydrogenation of amine boranes for chemical hydrogen storage. Int. J. Hydrogen Energy, https://doi.org/10.1016/j. ijhydene.2014.11.031 (2015).

28. Feng, W. et al. In situ facile synthesis of bimetallic CoNi catalyst supported on graphene for hydrolytic dehydrogenation of amine borane. Int. J. Hydrogen Energy, https://doi.org/10.1016/j.ijhydene.2013.12.113 (2014).

29. Cao, N., Su, J., Luo, W. \& Cheng, G. Hydrolytic dehydrogenation of ammonia borane and methylamine borane catalyzed by graphene supported Ru@Ni core-shell nanoparticles. Int. J. Hydrogen Energy, https://doi.org/10.1016/j.ijhydene.2013.10.059 (2014).

30. Wen, L., Zheng, Z., Luo, W., Cai, P. \& Cheng, G. Z. Ruthenium deposited on MCM-41 as efficient catalyst for hydrolytic dehydrogenation of ammonia borane and methylamine borane. Chinese Chem. Lett, https://doi.org/10.1016/j.cclet.2015.06.019 (2015).

31. Meng, X. et al. Graphene-supported trimetallic core-shell Cu@CoNi nanoparticles for catalytic hydrolysis of amine borane. Chempluschem, https://doi.org/10.1002/cplu.201300336 (2014).

32. Yang, L., Su, J., Luo, W. \& Cheng, G. Size-controlled synthesis of tetrametallic Ag@CoNiFe core-shell nanoparticles supported on graphene: A highly efficient catalyst for the hydrolytic dehydrogenation of amine boranes. ChemCatChem, https://doi.org/10.1002/ cctc.201400042 (2014).

33. Shen, J. et al. Hydrolytic dehydrogenation of amine-boranes catalyzed by graphene supported rhodium-nickel nanoparticles. Catal. Commun, https://doi.org/10.1016/j.catcom.2014.09.042 (2015).

34. Cao, N., Su, J., Luo, W. \& Cheng, G. Graphene supported Ru@Co core-shell nanoparticles as efficient catalysts for hydrogen generation from hydrolysis of ammonia borane and methylamine borane. Catal. Commun, https://doi.org/10.1016/j. catcom.2013.09.003 (2014).

35. Baguc, I. B. et al. Nanocrystalline metal organic framework (MIL-101) stabilized copper Nanoparticles: Highly efficient nanocatalyst for the hydrolytic dehydrogenation of methylamine borane. Inorganica Chim. Acta 483, 431-439 (2018).

36. Taçylldı, S., Demirkan, B., Karataş, Y., Gulcan, M. \& Sen, F. Monodisperse Ru[sbnd]Rh bimetallic nanocatalyst as highly efficient catalysts for hydrogen generation from hydrolytic dehydrogenation of methylamine-borane. J. Mol. Liq, https://doi.org/10.1016/j. molliq.2019.04.019 (2019).

\section{Acknowledgements}

The authors would like to thank Van Yuzuncu Yil and Dumlupinar Universities for funding.

\section{Author contributions}

M.G. and F.S. organized all experiments and wrote the manuscript. Y.K., E.K. and H.A. performed all experiments and characterizations. They have also drawn the figures.

\section{Competing interests}

The authors declare no competing interests.

\section{Additional information}

Supplementary information is available for this paper at https://doi.org/10.1038/s41598-019-55030-z.

Correspondence and requests for materials should be addressed to M.G. or F.S.

Reprints and permissions information is available at www.nature.com/reprints.

Publisher's note Springer Nature remains neutral with regard to jurisdictional claims in published maps and institutional affiliations.

(c) (i) Open Access This article is licensed under a Creative Commons Attribution 4.0 International License, which permits use, sharing, adaptation, distribution and reproduction in any medium or format, as long as you give appropriate credit to the original author(s) and the source, provide a link to the Creative Commons license, and indicate if changes were made. The images or other third party material in this article are included in the article's Creative Commons license, unless indicated otherwise in a credit line to the material. If material is not included in the article's Creative Commons license and your intended use is not permitted by statutory regulation or exceeds the permitted use, you will need to obtain permission directly from the copyright holder. To view a copy of this license, visit http://creativecommons.org/licenses/by/4.0/.

(C) The Author(s) 2019 